\title{
Burns resulting from spontaneous combustion of electronic cigarettes: a case series
}

\author{
Clifford Sheckter ${ }^{1}$, Arhana Chattopadhyay ${ }^{1}$, John Paro ${ }^{1}$ and Yvonne Karanas ${ }^{1,2^{*}}$
}

\begin{abstract}
Background: Electronic cigarette (e-cigarette) sales have grown rapidly in recent years, coinciding with a public perception that they are a safer alternative to traditional cigarettes. However, there have been numerous media reports of fires associated with e-cigarette spontaneous combustion.

Case Presentation: Three severe burns caused by spontaneous combustion of e-cigarettes within a 6-month period were treated at the Santa Clara Valley Medical Center Burn Unit. Patients sustained partial and full-thickness burns. Two required hospitalization and surgical treatment.

Conclusions: E-cigarettes are dangerous devices and have the potential to cause significant burns. Consumers and the general public should be made aware of these life-threatening devices.
\end{abstract}

Keywords: Electronic cigarettes, E-cigarette, E-cig, Burn

\section{Background}

Electronic cigarettes (e-cigarettes) have become increasingly popular in the world and the USA as an alternative to traditional cigarettes. The public at large sees these products as a safer means of nicotine consumption and as a tool to aid smoking cessation [1]. Use of e-cigarettes has increased by over $200 \%$ in the past 3 years in adults and increased ninefold in adolescents [2-4]. There are currently no scientific data that demonstrate that electronic cigarettes are any safer than traditional cigarettes. While public perceptions on safety primarily relate to historical health problems with tobacco products such as lung cancer and chronic pulmonary disease, there are no reports regarding how the public actually perceives the safety of the e-cigarette devices. However, there have been documented events in the media of spontaneous combustion events involving the electronic cigarette device [5-7]. Further, there have been case reports in both the USA and UK of e-cigarettes causing thermal, blast, and alkali burns from spontaneous combustion [8-10]. Most of these burns were sustained to the thigh

\footnotetext{
* Correspondence: Yvonne.Karanas@hhs.sccgov.org

${ }^{1}$ Division of Plastic Surgery, Stanford University, Palo Alto, CA, USA

${ }^{2}$ Santa Clara Valley Medical Center Regional Burn Center, 751 South Bascom

Avenue, San Jose, CA 95128, USA
}

(c) 2016 The Author(s). Open Access This article is distributed under the terms of the Creative Commons Attribution 4.0 International License (http://creativecommons.org/licenses/by/4.0/), which permits unrestricted use, distribution, and reproduction in any medium, provided you give appropriate credit to the original author(s) and the source, provide a link to the Creative Commons license, and indicate if changes were made. The Creative Commons Public Domain Dedication waiver (http://creativecommons.org/publicdomain/zero/1.0/) applies to the data made available in this article, unless otherwise stated.

\section{Case presentation}

Three cases were identified. The average burn TBSA was $8 \%$, ranging from 2 to $15 \%$. All patients had a mixture of partial- and full-thickness burns. The average

as e-cigarettes combusted in a pant pocket, although was $4 \%$ total body surface area (TBSA).

Our institution has encountered the immediate health effects of such combustion events. Two of three instances resulted in full-thickness burns requiring inpatient admission and surgery for excision and skin grafting. Herein, we the danger of electronic cigarette use.

We performed a retrospective chart review of all patients admitted to the Santa Clara Valley Medical Center Burn Center from July 2015 to April 2016. Patients who were treated for e-cigarette-related burns were identified. Their cases were reviewed to determine surgical treatments, extent of burns, depth of burns, length of stay, complications, and outcomes. Institutional Review Board approval and patient consent were obtained. 


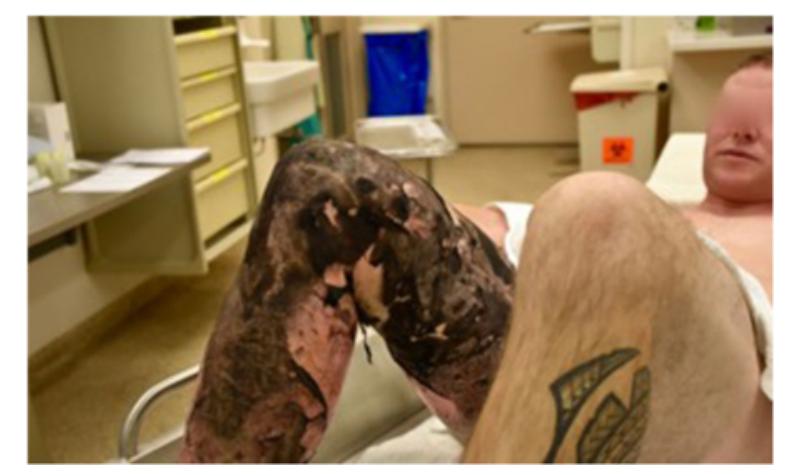

Fig. 1 Case 1, the right leg on admission

length of stay was 9 days ranging from 1 to 16 days. Two patients required inpatient admission and surgery. All the patients were male and habitual e-cigarette users. The average age at time of injury was 29 years old.

\section{Case 1}

A 34-year-old male with a history of ulcerative colitis and opioid dependence had placed an electronic cigarette in his right pant pocket which spontaneously combusted while shopping in public. His pants caught fire and were immediately removed to extinguish flames. He was brought to the emergency department by an ambulance.

Examination revealed a 15 \% TBSA circumferential deep partial-thickness and full-thickness burn of the right leg (Fig. 1). An epidural was placed for pain control, and on post-burn day 2, the patient was taken to the operating room for tangential excision with skin allograft placement to a $2000 \mathrm{~cm}^{2}$ surface area. The allografted areas were dressed with N-Terface (MEDLINE Industries, Inc., IL, USA) and ACTICOAT (Smith \& Nephew, London, UK), and the debrided superficial partial-thickness burns were dressed with Mepilex Ag (Molnlycke, Gothenburg, Sweden). On post-burn day 6, the allograft was removed, revealing healthy subcutaneous tissue ready for skin autografting. Two thousand four hundred square centimeters of meshed split-thickness skin grafts were used to cover

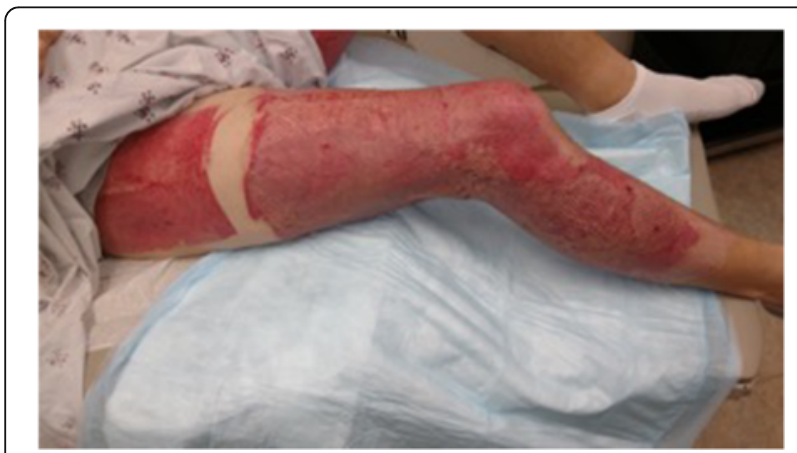

Fig. 2 Case 1, postoperative lateral view of the right leg

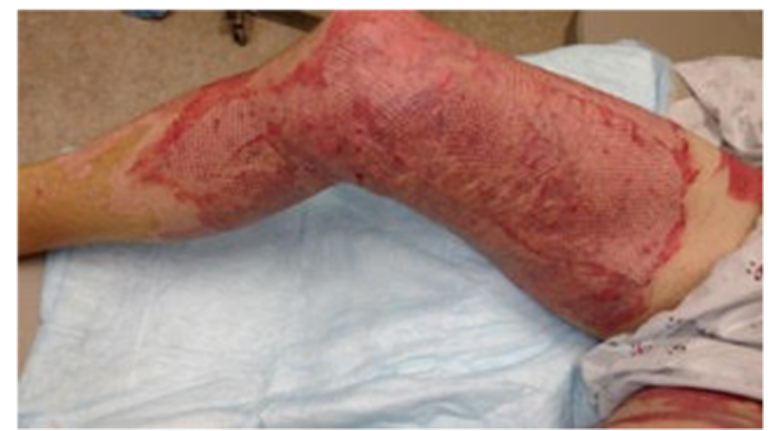

Fig. 3 Case 1, postoperative medial view of the right leg

the wounds. The autografts showed an excellent take on post-burn day 9, and the patient was discharged home on post-burn day 16 (Figs. 2 and 3).

\section{Case 2}

A 19-year-old otherwise healthy male had an electronic cigarette in his left pant pocket when it combusted and lit his pants on fire. He immediately removed his pants and rolled on the ground, which extinguished the flames. He was brought to the emergency department by an ambulance.

Examination revealed a $7 \%$ TBSA non-circumferential mixed partial- and full-thickness burn to the lateral thigh and calf (Fig. 4). On post-burn day 3, he was taken to the operating room for tangential excision and immediate split-thickness skin autografting of $800 \mathrm{~cm}^{2}$. The patient was discharged on post-burn day 9 with $100 \%$ graft take and healing wounds (Fig. 5).

\section{Case 3}

A 35-year-old otherwise healthy male sustained a $2 \%$ TBSA burn to his right lateral thigh when an e-cigarette device in the right back pocket of his pants spontaneously combusted, burning a hole through his pants (Fig. 6). Upon arrival to the emergency department, he was found to have partial- and full-thickness burns to

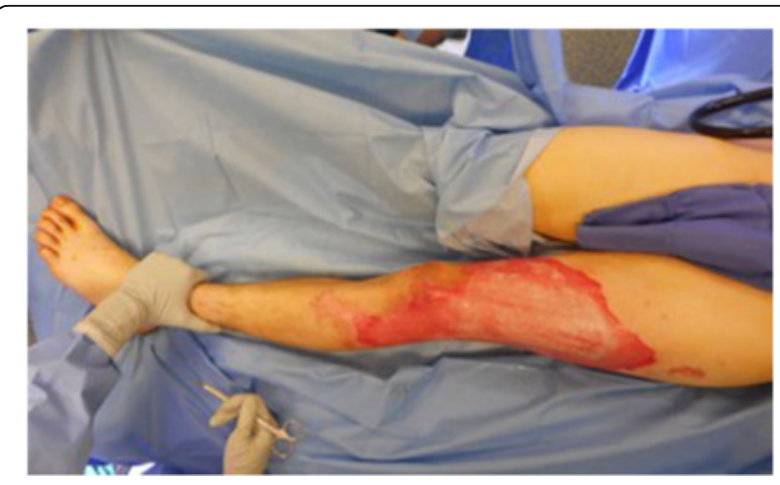

Fig. 4 Case 2, preoperative lateral view of the left leg 


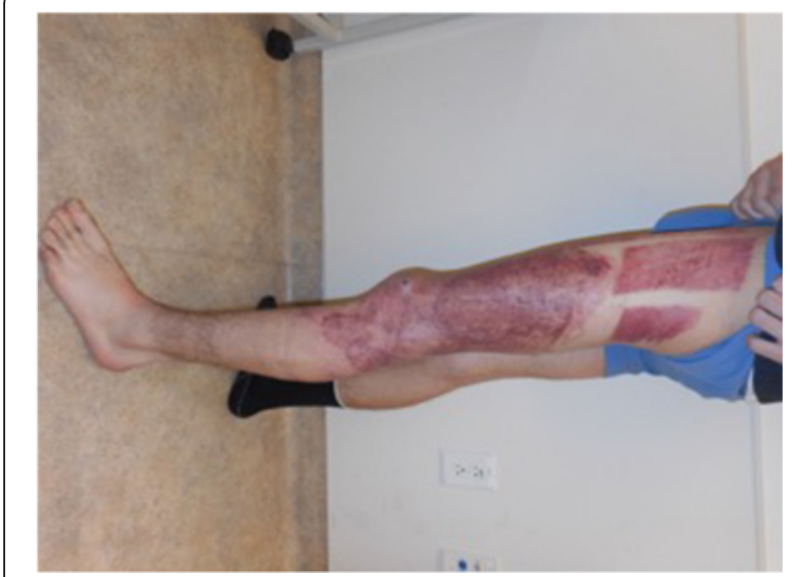

Fig. 5 Case 2, postoperative lateral view of the left leg

his right thigh (Fig. 7). The patient was treated in the outpatient setting with topical wound care. The patient elected for non-operative treatment and healed in 5 weeks.

\section{Conclusions}

Electronic cigarettes have been associated with at least 25 media reports of fires since 2009. This is likely an underestimation of the problem, as our institution encountered three e-cigarette burn victims in the span of 6 months. Furthermore, we illustrate two patients with 7 and $15 \%$ TBSA burns, larger than the previously reported e-cigarette burns [8-10]. Eighty percent of these reported fires were associated with charging e-

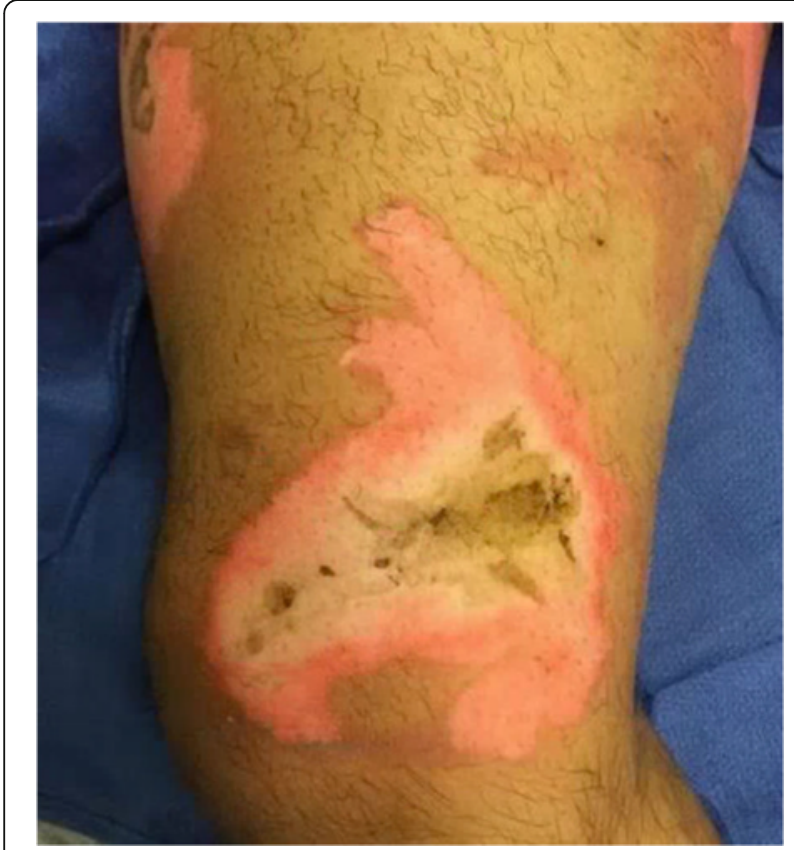

Fig. 6 Case 3, medial right thigh above the knee

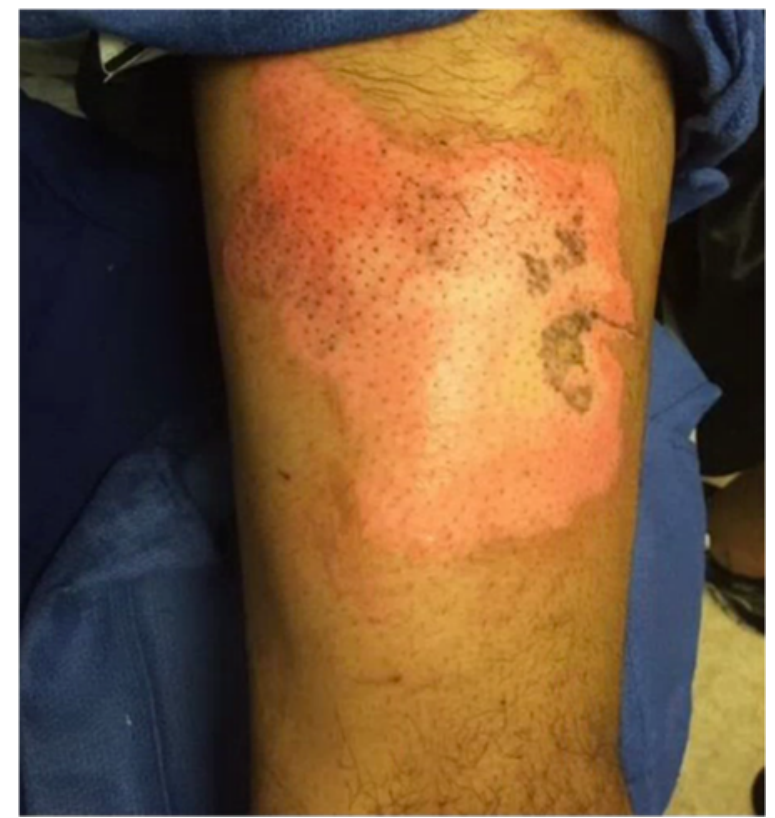

Fig. 7 Case 3, anterior right thigh

cigarettes in built-in USB ports in cars [11]. However, the voltage and current delivered to USB ports vary greatly, leading to "overcharging", excess thermal energy, and subsequent explosions.

All the patients in this report experienced e-cigarette combustion while carrying the e-cigarette device with a battery in a pocket. The cause of this type of explosion is a suspected failure of the lithium-ion battery interface. E-cigarettes contain a cylindrical battery enclosed in a thin metal cylinder with structural weakness at the ends (Fig. 8). When the electrolyte within the battery overheats, the cylinder is unable to withstand the internal pressure that builds up and ruptures the battery, causing

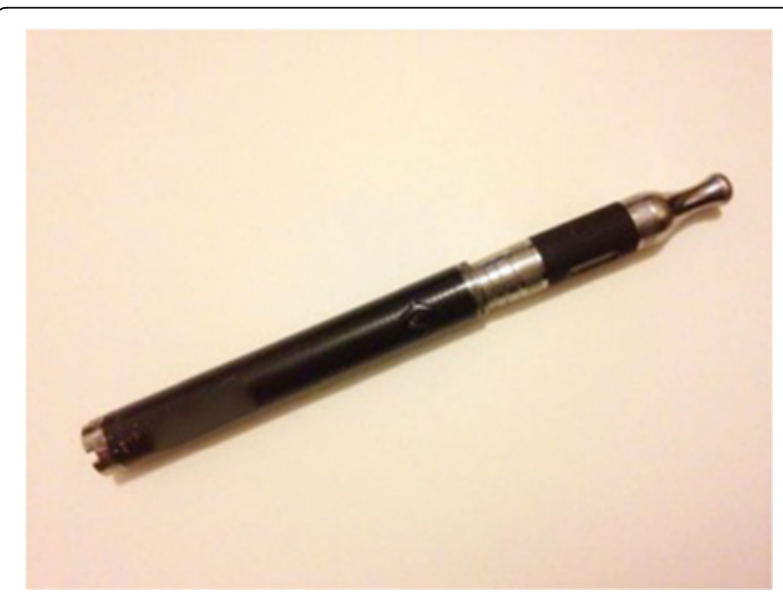

Fig. 8 Common electronic cigarette device containing a lithium-ion battery 
an explosion. The thermal energy from the explosion is clearly able to cause full-thickness burns leading to permanent disfigurement with risk for loss of limbs and life. In some cases, inpatient treatment and multiple surgeries are needed for effective treatment. Not only that this severely limits the lives of those affected but there is also a greater societal cost to the health system in managing these injuries.

In addition to the multiple ways that e-cigarettes cause fires, they also present a broader public health risk. A longitudinal cohort study found that e-cigarette users aged 16-26 were over eight times more likely to progress to traditional cigarettes compared to non-users [12]. E-cigarettes act as a "nicotine starter," slowly addicting users with fewer adverse side effects than traditional cigarettes. Eventually, as e-cigarette users become tolerant, they seek out the higher nicotine doses found in traditional cigarettes. Thus, the idea that e-cigarettes are a safer way to smoke is now becoming defunct.

Electronic cigarette devices spontaneously combust, have the ability to cause full-thickness burns, and act as a gateway to traditional cigarette use. While the public views these devices as benign and believes they offer a safer means to consume tobacco, these devices are dangerous and pose a serious public health risk.

\section{Acknowledgements}

No other acknowledgments are applicable.

\section{Funding}

There was no funding received regarding this manuscript or its contents.

\section{Availability of data and materials}

The discharge summaries and notes from the electronic medical record can be de-identified and made available to reviewers.

\section{Authors' contributions}

CS selected the patients and photographs. CS, AC, JP, and YK were major contributors to the writing of the manuscript. CS and JP are resident physicians in the Stanford Division of Plastic and Reconstructive Surgery Residency Program. AC is a medical student at Stanford. YK is the director of the SCVMC Regional Burn Center and an adjunct professor at Stanford Division of Plastic and Reconstructive Surgery. All authors read and approved the final manuscript.

\section{Competing interests}

The authors declare that they have no competing interests.

\section{Consent for publication}

Written informed consent was obtained from the patients for the publication of this case series and any accompanying images. A copy of the written consent is available for review by the Editor-in-Chief of this journal.

\section{Ethics approval and consent to participate}

The Santa Clara Valley Medical Center Institutional Review Board approved this study.

Received: 25 June 2016 Accepted: 18 August 2016

Published online: 12 December 2016

\section{References}

1. Nonnemaker J, Kim AE, Lee YO, MacMonegle A. Quantifying how smokers value attributes of electronic cigarettes. Tob Control. 2016;25(e1):e37-43.
2. Barrington-Trimis JL, Berhane K, Unger JB, Cruz TB, Huh J, Leventhal AM, Urman R, Wang K, Howland S, Gilreath TD, Chou C-P, Pentz MA, McConnell R. Psychosocial factors associated with adolescent electronic cigarette and cigarette use. Pediatrics. 2015;136(2):308-17.

3. Dutra LM, Glantz SA. Electronic cigarettes and conventional cigarette use among U.S. adolescents: a cross-sectional study. JAMA Pediatr. 2014;168(7):610-7

4. Wasowicz A, Feleszko W, Goniewicz ML. E-Cigarette use among children and young people: the need for regulation. Expert Rev Respir Med. 2015; 9(5):507-9.

5. Kulwicki MF. Child burned after e-cigarette explodes in car charger. Fox [Internet]. Salt Lake City; 2013. Available from: http://fox13now.com/2013/ 09/21/child-burned-after-e-cigarette-explodes-in-car-charger/?hpt=us_bn10. Accessed 25 May 2016.

6. Branson-Potts H. Woman burned by exploding e-cigarette battery awarded \$1.9 million. Los Angeles Times [Internet]. 2015. Available from: http://www.latimes.com/local/crime/la-me-ecigarette-burns-verdict20151001-story.html. Accessed 25 May 2016.

7. Rogér JM, Abayon M, Elad S, Kolokythas A. Oral trauma and tooth avulsion following explosion of e-cigarette. J Oral Maxillofac Surg. 2016;74(6):1181-5.

8. Kumetz EA, Hurst ND, Cudnik RJ, Rudinsky SL. Electronic cigarette explosion injuries: a case series. The American Journal of Emergency Medicine. 2016.

9. Nicoll KJ, Rose AM, Khan MAA, Quaba O, Lowrie AG. Thigh burns from exploding e-cigarette lithium ion batteries: first case series. Burns. 2016;42(4):e42-6.

10. Colaianni CA, Tapias LF, Cauley R, Sheridan R. Injuries caused by explosion of electronic cigarette devices. Eplasty. 2016;16:ic9.

11. United States Fire Administration. Electronic cigarette fires and explosions. FEMA [Internet]. 2014. Available from: https://books.google.com/ books?id=dqoYrgEACAAJ. Accessed 25 May 2016.

12. Primack BA, Soneji S, Stoolmiller M, Fine MJ, Sargent JD. Progression to traditional cigarette smoking after electronic cigarette use among US adolescents and young adults. JAMA Pediatr. 2015;169(11):1018-23.
Submit your next manuscript to BioMed Central and we will help you at every step:

- We accept pre-submission inquiries

- Our selector tool helps you to find the most relevant journal

- We provide round the clock customer support

- Convenient online submission

- Thorough peer review

- Inclusion in PubMed and all major indexing services

- Maximum visibility for your research

Submit your manuscript at www.biomedcentral.com/submit
Biomed Central 